\title{
Characterization of Burnout Among Spanish Family Physicians Treating Fibromyalgia Patients: The EPIFFAC Study
}

\author{
Xavier Torres, PhD, Begoña Ojeda, PhD, Antonio Collado, MD, PhD, Emilia Solé, MD, \\ Jesús Vergara, MD, PhD, Emili Gómez, MD, Xavier Castells, MD, PhD, and \\ Anna Arias, B.Sc. (OT, PT), MSc (E)
}

Objective: Burnout among physicians has increased, affecting not only doctors but also the quality of patient care. Treating challenging disorders, such as fibromyalgia, may increase the risk of feeling burned out. Health care of fibromyalgia patients is increasingly being assigned to family physicians. Therefore, we described the demographic characteristics, work contexts, component burnout scores (exhaustion, depersonalization, and personal accomplishment), and perceptions of fibromyalgia care of Spanish family medicine physicians with high and low levels of burnout. We then evaluated which of these variables were associated with having high or low levels of burnout.

Method: This cross-sectional study assessed 506 family physicians recruited from the Spanish Society of Family Physicians and randomly selected from Primary Health Care Centers. The subgrouping of family physicians based on their burnout scores was assessed by cluster analysis. Variables showing statistically significant differences between clusters and significance below 0.25 in univariate logistic regressions were assessed by multivariate logistic regression analysis.

Results: Family physicians reporting higher burnout scores (25\%) felt that fibromyalgia patients on sick leave increased their workload, reported no support from nurses in the treatment of fibromyalgia patients, and had a more negative impression of fibromyalgia patients.

Conclusions: One-quarter of family physicians reported feeling exhausted, detached from fibromyalgia patients, or less professionally accomplished. Several personal characteristics and contextual variables increased burnout. Several interventions to modify these variables and, thus, protect family physicians treating fibromyalgia from burnout are suggested. (J Am Board Fam Med 2020;33:386-396.)

Keywords: Chronic Disease, Cluster Analysis, Cross-Sectional Studies, Depersonalization, Family Physicians, Fibromyalgia, Logistic Models, Pain Management, Patient Care Team, Primary Health Care, Professional Burnout, Risk Factors, Workload

\section{Introduction}

In recent years, burnout among physicians has increased, with some authors reporting epidemic levels. ${ }^{1,2}$ Burnout affects a one-quarter to one-half

This article was externally peer reviewed.

Submitted 6 June 2019; revised 1 March 2019; accepted 3 March 2020.

From Unitat de Fibromiàlgia, Servei de Reumatologia, ICEMEQ, Hospital Clínic de Barcelona, Barcelona, Spain (BO, AC, EG, AA); Unitat de Fibromiàlgia, Servei de Psiquiatria i Psicologia, Institut Clínic de Neurociències, Hospital Clínic de Barcelona, Barcelona, Spain (XT); Joan XXIII University Hospital, Tarragona, Spain (ES); Unidad de Gestión Clínica Bajo Andarax, Almería, Spain (JV); Department of Epidemiology and Evaluation, IMIM (Hospital del Mar Medical Research Institute), Barcelona, Spain (XC). of physicians, ${ }^{3,4}$ increasing the likelihood of doctors reducing their work hours or even leaving medicine. ${ }^{5}{ }^{7}$ Burnout disrupts personal relationships ${ }^{8}$ and facilitates substance abuse, ${ }^{9,10}$ depression, ${ }^{11}$ and even suicidal thoughts. ${ }^{12,13}$ It also decreases the quality of patient care (as have been shown indirectly measured ${ }^{14,15}$ or reported by the physicians

\footnotetext{
Funding: The authors received no specific funding for this work.

Conflicting and Competing Interests: Authors declare no conflict of interests.

Corresponding author: Begoña Ojeda, $\mathrm{PhD}$, Unitat de Fibromiälgia, Servei de Reumatologia, ICEMEQ, Hospital Clínic de Barcelona, Barcelona, Spain (E-mail: begona. ojedaballesteros@gmail.com).
} 
themselves ${ }^{16}$ ), increases the rates of medical errors ${ }^{17}$ and economic costs, ${ }^{18}$ and reduces patient satisfaction. $^{19}$

The stressors, demands, and challenges that put physicians at risk of developing burnout vary with the specific working contexts and disorders encountered. According to the 2018 Medscape Family Physician Lifestyle Report, $47 \%$ of family physicians (FPs) reported feeling burned out, depressed, or both. In the same report, FPs came fourth in a list of physicians reporting unhappiness at work, after internists, intensivists, and cardiologists. Compared with other specialties, the practice of medicine in primary care may lack individual autonomy to a higher degree in terms of, for instance, deciding on how much time is needed to visit a patient. Burnout could even vary across specializations within the same specialty. That is, FPs with a workload mainly composed of treating challenging disorders could be at a higher risk of feeling burned out.

In Spain, as well as in other countries, ${ }^{20}$ the health care of fibromyalgia patients is increasingly being assigned to FPs. Treating a syndrome with a short-term, unstable, moderate-to-low therapeutic response might produce overwhelming demands that might erode a physician's sense of effectiveness. In fact, $41 \%$ of FPs complain that the diagnostic criteria of fibromyalgia are not sufficiently specific to properly guide a diagnosis. ${ }^{21}$ One-third of FPs report distrusting their ability to diagnose fibromyalgia and have serious doubts about the efficacy of currently available treatments, and more than $60 \%$ feel that they should be doing more to help their patients. $^{21}$ If treating fibromyalgia patients is also perceived as causing work overload and social conflict, exhaustion and cynicism might develop in FPs. ${ }^{22}$

For these reasons, we aimed to characterize the FPs reporting the highest levels of burnout. We expected higher scores for burnout in younger FPs reporting a higher work overload and fewer resources to treat fibromyalgia patients.

\section{Methods}

\section{Participants and Procedures}

The participants of this study consisted of Spanish FPs treating fibromyalgia patients. FPs were recruited from 2 different groups. One group included members of the Spanish Society of Primary Care Physicians (SEMERGEN). SEMERGEN is an academic society that includes about the $30 \%$ of FPs, mainly Spanish but also from other countries, working in Spain. The association sent an e-mail to 524 random members with a letter presenting the study, an invitation to participate, and a link to complete the survey online. Finally, 368 questionnaires were received and 278 were correctly completed and valid to participate in the study. This was a response rate of $51 \%$. The other group of participants included FPs randomly selected from a representative sample of Spanish Primary Health Care Centers. This subsample was selected following a previously described sampling procedure ${ }^{23}: 54$ Spanish Primary Health Care Centers out of the 2,980 included in the Catalog of Primary Care Centers of the National Health System were selected by a probability sampling procedure, with poly-staged, stratified cluster sampling. Forty-four additional Primary Health Care Centers were selected as reserves following the same procedure. Fifty-three Primary Health Care Centers agreed to participate in the study (acceptance rate, 54\%). The coordinators of each Primary Health Care Center conducted the same protocol to invite the FPs of their center to participate in the study. The distribution of Primary Health Care Centers was homogenous across the 17 Spanish Autonomous Communities. The response rate among physicians in the centers that finally participated was $22.1 \%$.

In both scenarios, 2 reminder invitations were sent out on a monthly basis. Participants did not receive any compensation for completing the survey.

\section{Instruments}

A survey was designed to assess the main variables previously identified as related to burnout. The survey was administered using computer-assisted online interviewing technology. The different blocks of this survey included the following.

Section 1: Demographic data (sex, age, and years of professional expertise)

A younger age and less professional experience seem consistently related to burnout. Some have suggested that burnout is higher in females, but results so far seem inconclusive. ${ }^{22}$

\section{Section 2: Maslach burnout inventory (MBI)}

The MBI is a 22-item questionnaire designed to assess the 3-dimensional construct of burnout: emotional exhaustion, depersonalization, and a 
sense of reduced personal accomplishment. Emotional exhaustion manifests itself through the loss of enthusiasm for work and feeling helpless, trapped, and defeated. Depersonalization occurs when doctors treat patients with indifference and objectify them and develop a negative attitude toward their colleagues and their profession. A sense of reduced personal accomplishment, or inefficiency, is characterized by the individual's withdrawal of responsibilities and detachment from work. ${ }^{22}$ The Spanish version of the MBI has been validated in different populations. ${ }^{24-26}$ According to the aims of our study, the wording of the MBI items was slightly modified to refer specifically to the treatment of fibromyalgia patients. MBI scores were transformed to fit a scale ranging from 0 to 100 .

Factor analysis of the Spanish version of the MBI with wording modified to refer specifically to the treatment of fibromyalgia patients confirmed the presence of a 3-factor structure coincident with those of previously described structures in Spanish samples, ${ }^{26}$ except for item 22 ("I have the feeling that my fibromyalgia patients blame me for some of their problems"), which loaded under Emotional Exhaustion instead of Depersonalization (Supplementary Material). The internal consistency of the MBI subscales was appropriate, with Cronbach's $\alpha$ being 0.92 for Emotional Exhaustion, 0.85 for Personal Accomplishment, and 0.74 for Depersonalization.

\section{Section 3: Workload due to fibromyalgia treat- ment and sense of control}

To evaluate this section, we included 27 items assessing (1) workload due to fibromyalgia, including the number of medical visits (ie, proportion of visits by fibromyalgia patients out of the total number of medical visits), as well as the subjective impression that, compared with other patients with chronic pain, fibromyalgia patients need a higher number of regular and extra visits, more time per visit, and medical reports more frequently; (2) the subjective impression that fibromyalgia patients on sick leave increases the medical workload (hinders treatment and increases the number of visits required); (3) personal resources, such as knowledge of fibromyalgia (from undergraduate and postgraduate studies) and knowledge of clinical guidelines both for diagnosis and treatment; and (4) access to external resources, including the availability of a treatment protocol specific for fibromyalgia patients, support from nurses, and access to specialists for diagnosis and treatment referral.

Section 4: Beliefs about the etiology of fibromyalgia and impression about patients

We included 2 questions on the beliefs of the FPs regarding the etiology of fibromyalgia (medical or psychosomatic) and whether fibromyalgia may cause an irreversible disability. Furthermore, a 13item survey assessing the FPs' agreement with negative statements about fibromyalgia patients compared with other patients with chronic disorders (eg, higher exaggeration of symptoms or excessively dramatic behavior) was designed $a d$ hoc based on the researchers' clinical experience. Agreement was measured on 4-point Likert scales ranging from absolutely agree to absolutely disagree (Table 1). Higher scores reflected a worse impression of fibromyalgia patients. The internal consistency of the 13 -item was appropriate (Cronbach's $\alpha=0.83$ ). The corrected item-total correlations ranged from 0.39 to 0.69 .

Finally, a visual analog scale $(0$ to $10 \mathrm{~cm})$ assessed the FPs' perception of treatment efficacy (ie, perceived degree of improvement in their fibromyalgia patients). Higher scores indicated a greater perception that fibromyalgia treatments were efficacious. Scores of both scales were transformed to fit a scale ranging from 0 to 100 .

\section{Statistical Analysis}

To verify the integrity of the factorial structure of the MBI in our sample, a principal component analysis involving varimax rotation with Kaiser normalization was calculated. Factor structure was further verified with split analyses by sex, median age, and random split half. Tucker's coefficients of congruence were calculated to verify the equality between subsamples. The internal consistency of the MBI subscales was assessed by Cronbach's alphas to verify homogeneity and interdependence between the items.

The internal consistency of the 13-item survey assessing the FPs' agreement with negative statements about fibromyalgia patients compared with other patients with chronic disorders was assessed by Cronbach's alphas.

The differences in the categorical variables between the participants randomly selected from a representative sample of Spanish Primary Health 
Table 1. Survey Assessing the Negative Impressions That Physicians Might Have of Fibromyalgia Patients*

\begin{tabular}{|c|c|}
\hline $\begin{array}{l}\text { Item } \\
\text { Number }\end{array}$ & Survey Statement \\
\hline 1 & $\begin{array}{l}\text { Fibromyalgia patients have difficulty specifying } \\
\text { their symptoms }\end{array}$ \\
\hline 2 & Fibromyalgia patients exaggerate their symptoms \\
\hline 3 & $\begin{array}{l}\text { Fibromyalgia patients do not comply with } \\
\text { therapeutic prescriptions }\end{array}$ \\
\hline 4 & $\begin{array}{l}\text { Fibromyalgia patients have had some negative } \\
\text { experience with health professionals }\end{array}$ \\
\hline 5 & Fibromyalgia patients have little initiative \\
\hline 6 & $\begin{array}{l}\text { Fibromyalgia patients do not assume their } \\
\text { share of the responsibilities in their treatment }\end{array}$ \\
\hline 7 & Fibromyalgia patients are never happy \\
\hline 8 & $\begin{array}{l}\text { Fibromyalgia patients consume more time of } \\
\text { health care professionals }\end{array}$ \\
\hline 9 & $\begin{array}{l}\text { Fibromyalgia patients consume more } \\
\text { medications }\end{array}$ \\
\hline 10 & $\begin{array}{l}\text { Fibromyalgia patients rely more on the internet } \\
\text { than on health care professionals }\end{array}$ \\
\hline 11 & $\begin{array}{l}\text { Fibromyalgia patients always ask for more } \\
\text { information about their disease }\end{array}$ \\
\hline 12 & $\begin{array}{l}\text { Fibromyalgia patients feel more frustrated by their } \\
\text { illness }\end{array}$ \\
\hline 13 & Fibromyalgia patients are excessively dramatic \\
\hline
\end{tabular}

*Measured by 4-point Likert scales ranging from absolutely agree to absolutely disagree. Original in Spanish.

Care Centers and SEMERGEN members who had agreed to participate voluntarily in the study were analyzed by the $\chi^{2}$ test. Differences in continuous variables between the groups were assessed by $t$ test for a comparison of means.

The potential subgrouping of FPs based on their burnout scores was assessed by a 2-step cluster analysis. To compare the characteristics of the subgroups defined by the 2-step cluster analysis, the $t$ test for a comparison of means for independent samples was conducted for continuous variables, along with the $\chi^{2}$ for categorical variables. The variables showing statistically significant differences between the FP subgroups, and a significance level below 0.25 in univariate logistic regression analy$\operatorname{ses}^{27}$ was included in the multivariate logistic regression analysis. A manual forward stepwise method based on the significance of the change in the log likelihood was applied to obtain and explore the different models. Finally, the adjustment and the clinical and theoretical importance of the models were assessed to obtain the best equation explaining the differences between the FP subgroups.

\section{Results}

The final sample contained 392 FPs (278 [71\%] were SEMERGEN members and 114 [29\%] were randomly selected from Spanish Primary Health Care Centers). SEMERGEN members were younger, with fewer years of professional expertise and reporting higher scores for Depersonalization. Although small, these differences were statistically significant (Table 2).

As a group, FPs did not report high scores in burnout (Table 3). However, cluster analysis identified 2 subgroups of FPs. Cluster $2(\mathrm{n}=99 ; 25 \%)$ showed higher scores in Emotional Exhaustion and Depersonalization and lower scores in Personal Accomplishment. Cluster 2 FPs were younger, had less professional expertise, and reported a higher

Table 2. Comparison between Family Physicians Recruited from the Spanish Society of Primary Care Physicians and Family Physicians Randomly Selected from Spanish Primary Health Care Centers

\begin{tabular}{|c|c|c|c|c|}
\hline Parameter & $\begin{array}{l}\text { Values for SEMERGEN } \\
\text { Members }(\mathrm{n}=278)\end{array}$ & $\begin{array}{l}\text { Values for Spanish } \\
\text { Primary Health Care } \\
\text { Centers }(\mathrm{n}=114)\end{array}$ & $\begin{array}{l}\mathrm{t} \text { Statistic } \\
\text { for } \chi^{2} \text { Test }\end{array}$ & $P$ \\
\hline Sex, n (\%) & & & 0.90 & 0.34 \\
\hline Female & $139(50)$ & $63(55.3)$ & & \\
\hline Male & $139(50)$ & $51(44.7)$ & & \\
\hline Age, mean (SD) & $49.3(11.2)$ & $51.8(9.1)$ & -2.3 & 0.02 \\
\hline Professional expertise (y), mean (SD) & $22.3(11.2)$ & $24.8(9.3)$ & -2.3 & 0.03 \\
\hline \multicolumn{5}{|l|}{ MBI, mean (SD) } \\
\hline Emotional Exhaustion & $31.4(20.9)$ & $30.0(20.6)$ & 0.6 & 0.55 \\
\hline Personal Accomplishment & $56.6(21.0)$ & $56.3(21.2)$ & 0.1 & 0.90 \\
\hline Depersonalization & $18.1(20.6)$ & $14.2(15.8)$ & 2.0 & 0.05 \\
\hline
\end{tabular}

SEMERGEN, Spanish Society of Primary Care Physicians; SD, standard deviation; MBI, Maslach Burnout Inventory. 
Table 3. Description of the Global Sample and Comparison between Clusters of Family Physicians Based on Their Burnout Scores

\begin{tabular}{|c|c|c|c|c|c|c|}
\hline \multirow[b]{2}{*}{ Parameter } & \multirow{2}{*}{$\begin{array}{l}\text { Total Sample } \\
\quad(\mathrm{n}=392)\end{array}$} & \multirow{2}{*}{$\begin{array}{l}\text { Values for Cluster } 1 \\
\qquad(\mathrm{n}=293)\end{array}$} & \multirow{2}{*}{$\begin{array}{l}\text { Values for Cluster } 2 \\
\qquad(\mathrm{n}=99)\end{array}$} & \multicolumn{2}{|c|}{$\begin{array}{l}\text { Statistics for } \\
\chi^{2} \text { Test }\end{array}$} & \multirow{2}{*}{$\begin{array}{c}P \text { for Univariate } \\
\text { Logistic } \\
\text { Regression }\end{array}$} \\
\hline & & & & $\mathrm{t}$ & $P$ & \\
\hline \multicolumn{7}{|l|}{ Sex, n (\%) } \\
\hline Female & $202(52)$ & $152(52)$ & $50(51)$ & 0.1 & 0.81 & 0.81 \\
\hline Male & $190(48)$ & $141(48)$ & $49(49)$ & & & \\
\hline Age, mean (SD) & $50.0(10.7)$ & $50.8(10.5)$ & $47.6(11.1)$ & 2.6 & 0.01 & 0.01 \\
\hline $\begin{array}{l}\text { Professional expertise }(\mathrm{y}) \text {, mean } \\
\text { (SD) }\end{array}$ & $23.0(10.7)$ & $23.7(10.6)$ & $21.2(11.0)$ & 2.0 & 0.04 & 0.04 \\
\hline \multicolumn{7}{|l|}{ Origin of sampling, $\mathrm{n}(\%)$} \\
\hline SEMERGEN & $278(71)$ & $201(69)$ & $77(78)$ & 3.0 & 0.08 & 0.08 \\
\hline $\begin{array}{l}\text { Spanish Primary Health Care } \\
\text { Centers }\end{array}$ & $114(29)$ & $92(31)$ & $22(22)$ & & & \\
\hline \multicolumn{7}{|l|}{ MBI, mean (SD) } \\
\hline Emotional Exhaustion & $31.0(20.8)$ & $22.5(14.2)$ & $55.9(17.0)$ & -19.2 & $<0.01$ & \\
\hline Personal Accomplishment & $56.5(21.1)$ & $61.0(20.7)$ & $43.3(16.1)$ & 8.8 & $<0.01$ & \\
\hline Depersonalization & $17.0(19.4)$ & $8.4(10.1)$ & $42.5(17.7)$ & -18.1 & $<0.01$ & \\
\hline \multicolumn{7}{|l|}{ Workload, n (\%) } \\
\hline $\begin{array}{l}\text { Proportion of fibromyalgia } \\
\text { visits }\end{array}$ & $10.8(23.7)$ & $9.9(23.0)$ & $13.5(25.6)$ & -1.2 & 0.22 & 0.22 \\
\hline $\begin{array}{l}\text { Fibromyalgia patients require } \\
\text { more regular visits than } \\
\text { other chronic pain } \\
\text { patients (Yes) }\end{array}$ & $255(65)$ & $176(60)$ & $79(80)$ & 12.7 & $<0.01$ & $<0.01$ \\
\hline $\begin{array}{l}\text { Fibromyalgia patients require } \\
\text { more extra visits than } \\
\text { other chronic pain } \\
\text { patients (Yes) }\end{array}$ & $164(42)$ & $101(35)$ & $63(64)$ & 25.9 & $<0.01$ & $<0.01$ \\
\hline $\begin{array}{l}\text { Fibromyalgia patients require } \\
\text { more time per visit than } \\
\text { other chronic pain } \\
\text { patients (Yes) }\end{array}$ & $311(79)$ & $221(75)$ & $90(91)$ & 10.8 & $<0.01$ & $<0.01$ \\
\hline $\begin{array}{l}\text { More than } 50 \% \text { of } \\
\text { fibromyalgia patients } \\
\text { require medical reports } \\
\text { (Yes) }\end{array}$ & $189(48)$ & $123(42)$ & $66(67)$ & 18.1 & $<0.01$ & $<0.01$ \\
\hline $\begin{array}{l}\text { Sick-leave in fibromyalgia } \\
\text { patients increases } \\
\text { workload compared to } \\
\text { other disorders (Yes) }\end{array}$ & $152(39)$ & $85(29)$ & $67(68)$ & 46.6 & $<0.01$ & $<0.01$ \\
\hline Hinders the treatment (Yes) & $134(88)$ & $73(86)$ & $61(91)$ & 1.0 & 0.33 & 0.33 \\
\hline $\begin{array}{l}\text { Increases number of visits } \\
\text { (Yes) }\end{array}$ & $143(94)$ & $79(93)$ & $64(96)$ & 0.5 & 0.50 & 0.50 \\
\hline \multicolumn{7}{|l|}{ Resources, n (\%) } \\
\hline \multicolumn{7}{|l|}{ Personal } \\
\hline $\begin{array}{l}\text { Perceived knowledge of } \\
\text { fibromyalgia (Relatively } \\
\text { high or Very high) }\end{array}$ & $172(44)$ & $132(45)$ & $40(40)$ & 0.6 & 0.42 & 0.39 \\
\hline $\begin{array}{l}\text { Did not receive education } \\
\text { about fibromyalgia }\end{array}$ & $109(28)$ & $78(27)$ & $31(31)$ & 0.8 & 0.37 & 0.37 \\
\hline $\begin{array}{l}\text { Education about } \\
\text { fibromyalgia acquired by } \\
\text { self-study }\end{array}$ & $267(68)$ & $201(69)$ & $66(67)$ & 0.1 & 0.72 & 0.72 \\
\hline
\end{tabular}




\begin{tabular}{|c|c|c|c|c|c|c|}
\hline \multirow[b]{2}{*}{ Parameter } & \multirow{2}{*}{$\begin{array}{l}\text { Total Sample } \\
\quad(\mathrm{n}=392)\end{array}$} & \multirow{2}{*}{$\begin{array}{l}\text { Values for Cluster } 1 \\
\qquad(\mathrm{n}=293)\end{array}$} & \multirow{2}{*}{$\begin{array}{l}\text { Values for Cluster } 2 \\
\qquad(\mathrm{n}=99)\end{array}$} & \multicolumn{2}{|c|}{$\begin{array}{l}\text { Statistics for } \\
\chi^{2} \text { Test }\end{array}$} & \multirow{2}{*}{$\begin{array}{l}P \text { for Univariate } \\
\text { Logistic } \\
\text { Regression }\end{array}$} \\
\hline & & & & $\mathrm{t}$ & $P$ & \\
\hline $\begin{array}{l}\text { Undergraduate education } \\
\text { about fibromyalgia }\end{array}$ & $60(15)$ & $44(15)$ & $16(16)$ & 0.1 & 0.79 & 0.79 \\
\hline $\begin{array}{l}\text { Education about } \\
\text { fibromyalgia acquired by } \\
\text { workshops }\end{array}$ & $157(40)$ & $123(42)$ & $34(34)$ & 1.8 & 0.18 & 0.18 \\
\hline $\begin{array}{l}\text { Knowledge and use of } \\
\text { Clinical Guides }\end{array}$ & $291(74)$ & $229(78)$ & $62(63)$ & 9.3 & $<0.01$ & $<0.01$ \\
\hline \multicolumn{7}{|l|}{ External } \\
\hline $\begin{array}{l}\text { Availability of a treatment } \\
\text { protocol for fibromyalgia } \\
\text { at own work center }\end{array}$ & $22(6)$ & $18(6)$ & $4(4)$ & 0.6 & 0.43 & 0.43 \\
\hline Support from nurse & $82(21)$ & $73(25)$ & $9(9)$ & 11.2 & $<0.01$ & $<0.01$ \\
\hline $\begin{array}{l}\text { Support from specialists } \\
\text { (diagnostic) }\end{array}$ & $360(2)$ & $271(93)$ & $89(90)$ & 0.7 & 0.41 & 0.41 \\
\hline $\begin{array}{l}\text { Support from specialists } \\
\text { (treatment) }\end{array}$ & $354(90)$ & $265(90)$ & $89(90)$ & 0.03 & 0.87 & 0.87 \\
\hline \multicolumn{7}{|l|}{ Beliefs about fibromyalgia } \\
\hline $\begin{array}{l}\text { Etiology of fibromyalgia } \\
\text { (psychosomatic) }\end{array}$ & $166(42)$ & $107(37)$ & $59(60)$ & 16.1 & $<0.01$ & $<0.01$ \\
\hline $\begin{array}{l}\text { Fibromyalgia is an } \\
\text { irreversibly disabling } \\
\text { disorder (yes) }\end{array}$ & $190(49)$ & $152(52)$ & $38(38)$ & 5.4 & 0.02 & 0.02 \\
\hline $\begin{array}{l}\text { Negative impression of } \\
\text { fibromyalgia patients }\end{array}$ & $59.2(12.7)$ & $56.7(11.7)$ & $66.4(12.5)$ & -7.0 & $<0.01$ & $<0.01$ \\
\hline $\begin{array}{l}\text { Perceived degree of } \\
\text { treatment efficacy }\end{array}$ & $55.0(14.8)$ & $56.2(14.7)$ & $51.2(14.5)$ & 2.94 & $<0.01$ & $<0.01$ \\
\hline
\end{tabular}

SEMERGEN, Spanish Society of Primary Care Physicians; SD, standard deviation; MBI, Maslach Burnout Inventory.

workload when treating fibromyalgia patients (ie, reported that fibromyalgia patients required more extra visits, time per visit, and medical reports), especially when the patients were on sick leave. Cluster 2 FPs also reported having fewer personal (knowledge and use of clinical guides) and external (support from nurses) resources for treating fibromyalgia. Fewer cluster 2 FPs believed that fibromyalgia might become an irreversibly disabling disorder, and a higher proportion considered fibromyalgia a psychosomatic disease. Cluster 2 FPs also reported a worse impression of fibromyalgia patients and a lower perception regarding the efficacy of fibromyalgia treatments (Table 3).

Multivariate logistic regression showed that FPs with higher scores in burnout were characterized as having the subjective impression that fibromyalgia patients on sick leave increased their workload, they had no support from nurses in the treatment of fibromyalgia patients, and they had a more negative impression of fibromyalgia patients. Not having support from nurses tripled the likelihood of the FPs belonging to cluster 2, and every point increasing the score on the survey assessing negative impressions about fibromyalgia patients multiplied the risk of burnout by 1.05 (Table 4).

\section{Discussion}

Most FPs do not report feeling burned out when treating fibromyalgia patients. However, onequarter reported feeling more emotionally exhausted, less professionally accomplished, or more detached from fibromyalgia patients. As previously observed, ${ }^{22}$ our results suggest that burnout increases with the confluence of personal characteristics and contextual variables related to the workplace. Indeed, FPs who reported higher scores in burnout were more likely to have the impression that fibromyalgia patients on sick leave increased their workload, report a lack of support from nurses, and have negative 
Table 4. Multivariate Logistic Regression Analysis of the Subgrouping of Family Physicians Based on Their Burnout Scores*

\begin{tabular}{|c|c|c|c|c|c|}
\hline Parameter & B & $\mathrm{SE}$ & $\begin{array}{l}\text { Odds Ratio } \\
(95 \% \mathrm{CI})\end{array}$ & $\begin{array}{c}\text { Change in }-2 \log \\
\text { likelihood }(P)\end{array}$ & $\begin{array}{l}\text { Nagelkerke } \\
\text { R2 }\end{array}$ \\
\hline \multicolumn{6}{|l|}{ Step 1} \\
\hline Origin of sampling & -0.47 & 0.27 & $0.62(0.37-1.07)$ & $3.13(0.08)$ & 0.01 \\
\hline \multicolumn{6}{|l|}{ Step 2} \\
\hline Origin of sampling & -0.41 & 0.27 & $0.67(0.39-1.14)$ & $5.67(0.02)$ & 0.03 \\
\hline Age & -0.03 & 0.01 & $0.97(0.05-0.99)$ & & \\
\hline Step 3 & & & & $46.42(<0.01)$ & 0.19 \\
\hline Origin of sampling & -0.41 & 0.29 & $0.66(0.37-1.18)$ & & \\
\hline Age & -0.03 & 0.01 & $0.97(0.95-0.99)$ & & \\
\hline Workload (sick leave in FM increases workload) & 1.67 & 0.26 & $5.29(3.21-8.72)$ & & \\
\hline Step 4 & & & & $14.43(<0.01)$ & 0.24 \\
\hline Origin of sampling & -0.44 & 0.30 & $0.64(0.36-1.15)$ & & \\
\hline Age & -0.03 & 0.01 & $0.97(0.95-0.99)$ & & \\
\hline Workload (sick leave in FM increases workload) & 1.71 & 0.26 & $5.50(3.30-9.18)$ & & \\
\hline Support from nurses & -1.38 & 0.40 & $0.25(0.11-0.56)$ & & \\
\hline Step 5 & & & & $19.71(<0.01)$ & 0.30 \\
\hline Origin of sampling & -0.40 & 0.31 & $0.67(0.37-1.23)$ & & \\
\hline Age & -0.03 & 0.01 & $0.97(0.95-0.99)$ & & \\
\hline Workload (sick leave in FM increases workload) & 1.43 & 0.27 & $4.16(2.44-7.01)$ & & \\
\hline Support from nurses & -1.13 & 0.41 & $0.32(0.15-0.72)$ & & \\
\hline Negative impression of fibromyalgia patients & 0.05 & 0.01 & $1.05(1.03-1.08)$ & & \\
\hline
\end{tabular}

*SE, standard error; FM, fibromyalgia; CI, confidence interval.

impressions of fibromyalgia patients than FPs with less burnout.

Overwork has been consistently related to burnout. Interventions directed at the workplace to eliminate the sources of stress have been shown to be effective. Reducing working hours, for instance, seems especially useful in improving burnout. ${ }^{2,28}$ Our results might add some specificity to these findings by indicating that it might be advisable to limit the number of fibromyalgia patients on sick leave assigned to each FP. Burnout has also been linked to unsatisfactory control in the workplace and low levels of decision making. In fact, a low sense of control over the conditions of practice has already been reported to be a powerful predictor of burnout in physicians. ${ }^{29,30}$ Therefore, our results might also suggest that protecting FPs' active participation and decision making in administering sick leave policies for fibromyalgia patients might increase their sense of control and reduce the risk of burnout. $^{31}$

In our study, having help from nurses differentiated the physicians with lower burnout scores. Unfortunately, this variable was assessed with a single unspecific item, making it impossible to define which kind of help and how much from nurses protected physicians from burnout. The most apparent benefit for physicians might be related to having additional help to manage the excessive workload and time pressure. ${ }^{22,32}$ Moreover, having help from nurses might increase the perception of social support. Previous studies have already shown that social support prevents exhaustion and depersonalization in teams of cancer care providers. ${ }^{33}$ Improving communication between team members also helps to prevent the development of burnout. $^{34,35}$ Therefore, individual interventions should be complemented with interventions targeting work conditions. Increasing the amount of technical help from nurses to manage work overload while simultaneously supporting work group cohesion and a healthy work climate might be the most effective way for reducing the risk of burnout in physicians. ${ }^{36}$ Several such interventions have already shown promising results in nurses ${ }^{37}$ and residents. ${ }^{38}$

The most controversial finding in our study might be that the physicians most affected by burnout had a worse impression of fibromyalgia patients 
(eg, fibromyalgia patients exaggerate their symptoms, do not assume their share of the responsibilities in their treatment, or are excessively dramatic). The odds ratio of having a worse impression of fibromyalgia patients showed that every unit increasing in the score of the survey multiplied by 1.05 the risk of pertaining to the group of FPs with a higher level of burnout. Considering that the survey is composed of 13 items with scores ranging from 0 to 3 , having negative impressions about fibromyalgia patients might multiply as much as 40.95 times the risk of suffering the highest levels of burnout. The cross-sectional design of our study did not enable us to determine whether physicians with burnout develop a worse impression of fibromyalgia patients or whether these bad impressions lead to the development of burnout. Because burnout develops when demands exceed resources, treating a complex disorder such as fibromyalgia with a low rate of clinical success might place physicians at a higher risk of feeling frustrated and resourceless. A lack of intrinsic reward at work (in our case, being able to help patients) has also been linked to an increased risk of feeling burned out. ${ }^{39}$

The authors of the MBI suggested that the burnout component of Exhaustion might lead to the deployment of actions that distance oneself from work as a way of coping with work overload. In the same vein, they suggested that the most probable sequential development of burnout goes from exhaustion to depersonalization. ${ }^{22}$ If this was the case, developing a bad impression of fibromyalgia patients would follow the initial phases of burnout and aggravate the development of distancing as a reaction to exhaustion. This is especially relevant because burnout states include the belief that additional personal efforts do not lead to better results.

Negative impressions of fibromyalgia patients also might not affect FPs directly by promoting burnout but might affect the relationship between the patient and the physician. This could lead to patients believing that their doctor is detached and not compassionate. A poor relationship might interfere with treatment efficacy which, especially for medically unexplained physical symptoms, seems largely based on a collaborative patient-doctor relationship. ${ }^{40}$ Indeed, at least 1 study has shown that one-quarter of Canadian FPs describe fibromyalgia patients as malingerers, in some cases accusing the patients of malingering. ${ }^{21}$ The same study described a vicious circle involving the frustration of doctors treating patients with vague symptoms who demand incessant relief and support and patients' perception of lack of support or even dislike by doctors.

Several variables were observed to be less relevant for burnout in our study compared with previous studies, such as the physicians' perceived knowledge of fibromyalgia and familiarity with diagnostic criteria and treatment modalities. ${ }^{41-43}$ In our study, knowledge of fibromyalgia was excluded from the final model of burnout. However, our results highlighted the relevance of knowing the real person with fibromyalgia in the development of burnout. In our experience, the preconceived perceptions of clinical psychology residents regarding fibromyalgia patients change substantially after rotation in our unit. Similarly, increasing education about fibromyalgia patients during rotations in rheumatology departments has shown promising results. ${ }^{43}$

Burnout seems especially common during residency $^{44}$ and in younger physicians, ${ }^{45,46}$ possibly because the risk of burnout increases with lower levels of work experience. ${ }^{22}$ However, it has been also suggested that younger primary care physicians put more effort into their relationship with patients, which increases patient satisfaction regarding their communication with physicians, but also causes higher levels of emotional exhaustion in doctors. ${ }^{47}$ In our study, neither age nor professional experience explained a significant proportion of burnout. However, we did not assess the level of investment made by the FPs in their relationship with patients. Future studies could research the effects of the FPs' efforts in communicating with patients and the subjective discordance between their investment and reward. Meanwhile, it seems advisable to inform younger physicians that perceiving a lack of social reward may increase the risk of feeling burned out. $^{48,49}$

\section{Limitations}

The physicians' personality was not assessed in our study. Physicians with higher scores for personality dimensions, such as neuroticism (proneness to negative affectivity) and introversion (difficulties in experiencing positive emotions), have been described to be more vulnerable to burnout, as well as those with low agreeableness. ${ }^{50,51}$

We did not assess depressive and anxiety symptoms among FPs. Burnout seems to be more 
context-specific than driven by depression, and individuals with burnout show a lower pathologic profile than depressive ones. However, we do not know the extent to which the higher scores for burnout were due to the presence of depressive or anxiety disorders. This limitation might also confound conclusions about the influence of personal and work variables on the risk of developing burnout.

In conclusion, one-quarter of Spanish FPs characterized by perceiving a higher workload, lacking help from nurses, and having negative impressions of fibromyalgia patients reported higher burnout scores related to the treatment of fibromyalgia patients. Our results might help to improve organization and physician-directed interventions that have been shown to be effective in protecting FPs from burnout. ${ }^{52}$

Burnout has been consistently and negatively linked to patient care, ${ }^{53}$ the physicians' physical and mental health, ${ }^{11,12}$ job absenteeism, effectiveness at work, ${ }^{10}$ and personal conflicts with colleagues. ${ }^{54,55}$ Ultimately, all these problems might compromise the viability of health care organizations. Therefore, identification of these risk factors seems crucial for designing effective interventions to protect the health of physicians and to improve the care of fibromyalgia patients.

The authors express their gratitude to all Spanish FPs who agreed to participate in the study, to the Spanish Society of Primary Care Physicians (SEMERGEN) for their technical help with the computer-assisted online interviewing tool, and to the following Primary Health Centers coordinators for their help during the research: Casilda Castillo (CS Pedro Martínez, Granada), José María Martín-Aragón (CS Baeza, Baeza, Jaen), Dolores Risquez (CS Martos, Martos, Jaen), Adela Alcalá (CS La Granja), Dr. Manuel Blanco (Jerez de la Fra, Cádiz), Marta Marco Gracia (CS Sarrión, Sarrión, Teruel), Ana Isabel Domínguez (CS Zuera, Zuera, Zaragoza), María del Carmen Gallardo (CS Teruel Ensanche, Teruel), Carmelo Ariaga (CS Casetas, Zaragoza), Juan Navarro (CS Navia, Navia), José Cachón Fernández (CS La Magdalena, Avilés), José Manuel Fernández (CS Pumarín, Oviedo), Alicia Martínez (CS Tramuntana, Esporles, Palma de Mallorca), Midiala Díaz (CS Canal Salat, Ciutadella, Menorca), Bernart Montserrat (CS S'Escorxador, Palma de Mallorca), Rafael Medina (CS Tazacorte, Tazacorte, Santa Cruz de Tenerife), Ana Gajate (CS Morro Jable, Morro Jable, Las Palmas), Elena Pérez (SC San Juan, Telde, Las Palmas), Olga Peña (CS Laredo Laredo), Adelino Saiz (CS Zapatón, Torrelavega), Ana Galván Mansó (CS Castillo-Hermida, Santander), Mariano Pérez Alonso (CS Fuentes de Oñoro, Fuentes de Oñoro, Salamanca), Eva Sánchez Martín (CS Parada del Molino, Zamora), Juan Ignacio López Gil (CS José Aguado, León), Rosa Orugo (CS Solana del Pino, Solanada del Pino, Ciudad Real), Rafael Fernández González (CS Villarrobledo, Villarrobledo, Albacete), Juan López Abrir
(CS Zona 3 Villacerrada, Albacete), Concepción Medina (CS Berguedá, Berga, Barcelona), Albert Gómez Sorribes (CS L'Ametlla de Mar, L'Ametlla de Mar, Tarragona), Beatriz Arizaga (CS EAP 17 de Setembre, El Prat de Llobregat, Barcelona), Eva Pablos (CS Sant Oleguer, Sabadell, Barcelona), Oscar Peral (CS Vila Olímpica, Barcelona), Paula Gómez (CS Creu Alta, Sabadell, Barcelona), Adolfo Rodríguez Nieto (CS Dolores, Dolores, Alicante), Ramón Salvador (CS Mislata, Mislata, Valencia), José Vicente Lozano (CS Valencia Serrería 2, Valencia), Consuelo de Tena (CS Logrosán, Logrosán, Cáceres), Antonio Arbizu (CS Mérida Urbano III, Obispo Paulo) (Mérida, Badajoz), María José García de Vinuesa Palo (CS Badajoz Zona Centro, Badajoz), Manuel Palmeiro Díaz (CS Baralla, Baralla, Lugo), Elvira Sineiro (CS de San Roque, Vilagarcía de Arousa, Pontevedra), Francisco Javier Paredes (CS Rosalía de Castro, Vigo, Pontevedra), Montse Toscano (CS Collado Villalba Estación, Collado Villalba), María Salud Molina (CS El Soto, Móstoles), María Dolores Fuentes (CS Santomera, Santomera), Encarnación Madrid (CS Torre Pacheco Este, Torre Pacheco), José Gómez (CS Monteagudo, Monteagudo), Juan Carlos Tres Belzunegui (CS Aoiz Agoitz, Aoiz), Fernando Merino Muñoz (CS Tudela Este, Tudela), Pablo Pascual (CS Azpilagaña, Pamplona), Jon Isasi Otaolea (CS Gorliz, Gorliz, Vizcaya), José Ignacio Beristain (CS Astrabudua, Astrabudua, Vizcaya), María Jesús Ezquerra (CS Murillo, Murillo de Río leza), and Paula Guerrero (CS Calahorra, Calahorra).

To see this article online, please go to: http://jabfm.org/content/ 33/3/386full.

\section{References}

1. Ripp J. CHARM-Gold Charter on Physician Wellbeing now published in JAMA. Available from: http://www.gold-foundation.org/newsroom/news/ charm-gold-charter/. Published 2018. Accessed July 25, 2018.

2. West CP, Dyrbye LN, Erwin PJ, et al. Interventions to prevent and reduce physician burnout: a systematic review and meta-analysis. Lancet 2016;388:2272-81.

3. Linzer $M$, Visser MR, Oort FJ, et al. Predicting and preventing physician burnout: results from the United States and the Netherlands. Am J Med 2001;111:170-5.

4. Grassi L, Magnani K. Psychiatric morbidity and burnout in the medical profession: an Italian study of general practitioners and hospital physicians. Psychother Psychosom 2000;69:329-34.

5. Sinsky CA, Dyrbye LN, West CP, et al. Professional satisfaction and the career plans of US physicians. Mayo Clin Proc 2017;92:1625-35.

6. Rabatin J, Williams E, Baier Manwell L, et al. Predictors and outcomes of burnout in primary care physicians. J Prim Care Community Health 2016;7: 41-3.

7. Shanafelt TD, Hasan O, Dyrbye LN, et al. Changes in burnout and satisfaction with work-life balance in physicians and the general US working population between 2011 and 2014. Mayo Clin Proc 2015;90:1600-13. 
8. Burke RJ, Greenglass ER. Hospital restructuring, work-family conflict and psychological burnout among nursing staff. Psychol Health 2001;16:583-94.

9. Marmon LM, Heiss K. Improving surgeon wellness: the second victim syndrome and quality of care. Semin Pediatr Surg 2015;24:315-8.

10. Nicola R, McNeeley MF, Bhargava P. Burnout in radiology. Curr Probl Diagn Radiol 2015;44:389-90.

11. Wurm W, Vogel K, Holl A, et al. Depressionburnout overlap in physicians. PLoS One 2016;11: e0149913.

12. van der Heijden F, Dillingh G, Bakker A, et al. Suicidal thoughts among medical residents with burnout. Arch Suicide Res 2008;12:344-6.

13. Lacy BE, Chan JL. Physician burnout: the hidden health care crisis. Clin Gastroenterol Hepatol 2018;16:311-7.

14. Kushnir T, Greenberg D, Madjar N, et al. Is burnout associated with referral rates among primary care physicians in community clinics? Fam Pract 2014;31:44-50.

15. Shanafelt TD, Mungo M, Schmitgen J, et al. Longitudinal study evaluating the association between physician burnout and changes in professional work effort. Mayo Clin Proc 2016;91:422-31.

16. Shanafelt TD, Bradley KA, Wipf JE, et al. Burnout and self-reported patient care in an internal medicine residency program. Ann Intern Med 2002;136:358-67.

17. Salyers MP, Bonfils KA, Luther L, et al. The relationship between professional burnout and quality and safety in healthcare: a meta-analysis. J Gen Intern Med 2017;32:475-82.

18. Kalia M. Assessing the economic impact of stressthe modern day hidden epidemic. Metabolism 2002;51:49-53.

19. Haas JS, Cook EF, Puopolo AL, et al. Is the professional satisfaction of general internists associated with patient satisfaction? J Gen Intern Med 2000;15:122-8.

20. Perrot S, Dickenson AH, Bennett RM. Fibromyalgia: harmonizing science with clinical practice considerations. Pain Pract 2008;8:177-89.

21. Hayes SM, Myhal GC, Thornton JF, et al. Fibromyalgia and the therapeutic relationship: Where uncertainty meets attitude. Pain Res Manag 2010;15:385-91.

22. Maslach C, Schaufeli WB, Leiter MP. Job burnout. Annu Rev Psychol 2001;52:397-422.

23. Collado A, Gomez E, Coscolla R, et al. Work, family and social environment in patients with fibromyalgia in Spain: an epidemiological study: EPIFFAC study. BMC Health Serv Res 2014;14:513.

24. Gil-Monte PR. Factorial validity of the Maslach Burnout Inventory (MBI-HSS) among Spanish professionals. Rev Saúde Pública 2005;39:1-8.
25. Montiel-Company JM, Subirats-Roig C, FloresMartí P, et al. Validation of the Maslach Burnout Inventory-human services survey for estimating burnout in dental students. J Dent Educ 2016;80: 1368-75.

26. García JM, Herrero S, León J. Validez factorial del Maslach Burnout Inventory (MBI) en una muestra de trabajadores del Hospital Psiquiátrico Penitenciario de Sevilla. Apunt Psicol 2007;25:157-73.

27. Hosmer DW, Lemeshow S. Applied logistic regression. 2nd ed. NewYork (NY): Wiley; 2000.

28. Gopal R, Glasheen JJ, Miyoshi TJ, et al. Burnout and internal medicine resident work-hour restrictions. Arch Intern Med 2005;165:25952600.

29. Southwick FS, Southwick SM. The loss of a sense of control as a major contributor to physician burnout. JAMA Psychiatry 2018;75:665.

30. Freeborn DK. Satisfaction, commitment, and psychological well-being among HMO physicians. West J Med 2001;174:13-8.

31. Shanafelt TD, Dyrbye LN, West CP. Addressing physician burnout: the way forward. JAMA 2017; 317:901-2.

32. Cordes CL, Dougherty TW. A review and an integration of research on job burnout. AMR 1993; 18:621-56.

33. Le Blanc PM, Hox JJ, Schaufeli WB, et al. Take care! The evaluation of a team-based burnout intervention program for oncology care providers. J Appl Psychol 2007;92:213-27.

34. Lee S, Crockett MS. Effect of assertiveness training on levels of stress and assertiveness experienced by nurses in Taiwan, Republic of China. Issues Ment Health Nurs 1994;15:419-32.

35. Rø KEI, Gude T, Tyssen R, et al. Counselling for burnout in Norwegian doctors: one year cohort study. BMJ 2008;337:a2004.

36. Thomas LR, Ripp JA, West CP. Charter on physician well-being. JAMA 2018;319:1541-1542.

37. Shimizu T, Mizoue T, Kubota S, et al. Relationship between burnout and communication skill training among Japanese hospital nurses: a pilot study. Jrnl of Occup Health 2003;45:185-90.

38. Dabrow S, Russell S, Ackley K, et al. Combating the stress of residency: one school's approach. Acad Med 2006;81:436-9.

39. Siefert K, Jayaratne S, Chess WA. Job satisfaction, burnout, and turnover in health care social workers. Health Soc Work 1991;16:193-202.

40. Richardson RD, Engel CC. Evaluation and management of medically unexplained physical symptoms. Neurologist 2004;10:18-30.

41. Kianmehr N, Haghighi A, Bidari A, et al. Are general practitioners well informed about fibromyalgia? Int J Rheum Dis 2017;20:1917-21. 
42. Blotman F, Thomas E, Myon E, et al. Awareness and knowledge of fibromyalgia among French rheumatologists and general practitioners. Clin Exp Rheumatol 2005;23:697-700.

43. Buskila D, Neumann L, Sibirski D, et al. Awareness of diagnostic and clinical features of fibromyalgia among family physicians. Fam Pract 1997;14:238-41.

44. Dyrbye LN, West CP, Satele D, et al. Burnout among U.S. medical students, residents, and early career physicians relative to the general U.S. population. Acad Med 2014;89:443-51.

45. Spickard A, Gabbe SG, Christensen JF. Mid-career burnout in generalist and specialist physicians. JAMA 2002;288:1447-50.

46. Keeton K, Fenner DE, Johnson TRB, et al. Predictors of physician career satisfaction, work-life balance, and burnout. Obstet Gynecol 2007;109: 949-55.

47. Windover AK, Martinez K, Mercer MB, et al. Correlates and outcomes of physician burnout within a large academic medical center. JAMA Intern Med 2018;178:856.

48. Maslach C, Leiter MP. Understanding the burnout experience: recent research and its implications for psychiatry. World Psychiatry 2016;15:103-11.
49. Holmes EG, Connolly A, Putnam KT, et al. Taking care of our own: a multispecialty study of resident and program director perspectives on contributors to burnout and potential interventions. Acad Psychiatry 2017;41:159-66.

50. Wiederhold BK, Cipresso P, Pizzioli D, et al. Intervention for physician burnout: a systematic review. Open Med (Wars) 2018;13:253-63.

51. McManus I, Keeling A, Paice E. Stress, burnout and doctors' attitudes to work are determined by personality and learning style: a twelve year longitudinal study of UK medical graduates. BMC Med 2004;2:29.

52. Panagioti M, Panagopoulou E, Bower $\mathrm{P}$, et al. Controlled interventions to reduce burnout in physicians. JAMA Intern Med 2017;177:195.

53. Cebrià J, Sobrequés J, Rodríguez C, et al. Influencia del desgaste profesional en el gasto farmacéutico de los médicos de atención primaria. Gac Sanit 2003;17:483-9.

54. West CP, Dyrbye LN, Shanafelt TD. Physician burnout: contributors, consequences and solutions. J Intern Med 2018;283:516-29.

55. Winkel AF, Honart AW, Robinson A, Jones AA, Squires A. Thriving in scrubs: a qualitative study of resident resilience. Reprod Health 2018;15:53. 